\title{
Substantial increase in minimum lake surface temperatures under climate change
}

\section{R. lestyn Woolway ${ }^{1,2}$ (D) Gesa A. Weyhenmeyer ${ }^{3}$ - Martin Schmid ${ }^{4}$. Martin T. Dokulil ${ }^{5}$ - Elvira de Eyto ${ }^{6}$. Stephen C. Maberly ${ }^{7} \cdot$ Linda May $^{8}$ • Christopher J. Merchant ${ }^{1,9}$}

Received: 11 December 2018 / Accepted: 6 May 2019 / Published online: 15 May 2019

(C) The Author(s) 2019

\begin{abstract}
The annual minimum of lake surface water temperature influences ecological and biogeochemical processes, but variability and change in this extreme have not been investigated. Here, we analysed observational data from eight European lakes and investigated the changes in annual minimum surface water temperature. We found that between 1973 and 2014, the annual minimum lake surface temperature has increased at an average rate of $+0.35^{\circ} \mathrm{C} \mathrm{decade}{ }^{-1}$, comparable to the rate of summer average lake surface temperature change during the same period $\left(+0.32{ }^{\circ} \mathrm{C} \mathrm{decade}^{-1}\right)$. Coherent responses to climatic warming are observed between the increase in annual minimum lake surface temperature and the increase in winter air temperature variations. As a result of the rapid warming of annual minimum lake surface temperatures, some of the studied lakes no longer reach important minimum surface temperature thresholds that occur in winter, with complex and significant potential implications for lakes and the ecosystem services that they provide.
\end{abstract}

Keywords Warming $\cdot$ Water $\cdot$ trends $\cdot$ Extremes $\cdot$ Winter limnology

\section{Introduction}

Several studies have investigated the impacts of climate change on lake surface water temperature (Livingstone 2003; O'Reilly et al. 2015; Magee et al. 2016). These have provided overwhelming evidence that lakes are warming on a global scale, with some lakes warming faster than local surface air temperatures (Austin and Colman 2007; Schneider and Hook 2010; O'Reilly et al. 2015). The current rate of warming is unprecedented since the start of the twentieth century (Woolway et al. 2017a). However, while there is sufficient evidence to demonstrate that lakes are warming, most long-term analyses have focused on summer-average lake surface temperature

Electronic supplementary material The online version of this article (https://doi.org/10.1007/s10584-01902465-y) contains supplementary material, which is available to authorized users.

\section{R. Iestyn Woolway}

riwoolway@gmail.com

Extended author information available on the last page of the article 
trends, investigating either single-point observations (Schneider and Hook 2010; O'Reilly et al. 2015), lake-wide averages (Woolway and Merchant 2017) or spatially resolved temperatures from satellites (Woolway and Merchant 2018). Temperature changes during other seasons have received comparatively little attention, focusing either on single lakes or a small number of lakes within a specific region (Lenters 2004; Schmid and Köster 2016; Winslow et al. 2017; Woolway et al. 2017a). Previous studies have also focused typically on the influence of climate change on monthly, seasonal or annually averaged observations. However, the cold extreme of minimum lake surface temperature attained within any given year is also highly pertinent to a large variety of physical, chemical and biological processes.

Winter temperature is of great importance to lake ecosystems, and the annual minimum temperature sets a strong control on many processes occurring in lakes (Hampton et al. 2017). Higher winter temperatures, previously inferred from the analysis of isolated extreme events (e.g., the mild winter of 2006-2007 in Europe), have been shown to have a striking and long-lasting influence on lake ecology (Straile et al. 2003; Rempfer et al. 2010; Straile et al. 2010), including the distribution and population dynamics of species (Straile and Stenseth 2007). Winter lake surface temperatures influence the formation of ice cover, a process that has a direct effect on many lake ecosystem processes (Hampton et al. 2017; Sharma et al. 2019). Surface temperature during winter can also affect the duration of the period of homothermy, a state in which deep lakes can mix fully, allowing the transport of oxygen from surface to deep waters and the transport of dissolved nutrients in the opposite direction (Straile et al. 2003). Surface temperature change during winter can therefore be very informative of stratification dynamics and can provide useful information on the lake thermal environment, which will have repercussions throughout the year in terms of biogeochemistry, organismal metabolism and the availability of suitable habitat for biota.

Some modelling studies have predicted an increase in lake minimum temperature with climate change (Elo et al. 1998; Fang and Stefan 1999). However, relatively little has been reported directly from observations about how minimum lake surface temperatures have responded to climatic variability and trends. Thus, there are still substantial gaps in knowledge of how minimum lake surface temperatures respond to warming, in particular at the regional and global scale. In this study, we analysed how annual minimum lake surface temperatures have changed based on long-term in situ lake surface temperature observations from some of Europe's best-monitored lakes. Unlike seasonally averaged lake temperature studies, where many observations are used to calculate long-term trends, the minimum lake surface temperature is based on a single extreme value each year and, thus, has greater inter-annual variability. The variability makes the effects of climate change more difficult to detect, a reason why we selected only lakes with long (> 40 years) observational records. In addition, we restricted our analyses to lakes that usually do not freeze during winter since the annual minimum surface water temperature of ice-covered lakes is $0{ }^{\circ} \mathrm{C}$, and therefore per default, there cannot be a trend. The main intention of this study was to analyse the temporal development of annual minimum lake surface temperatures across Europe.

\section{Methods}

\subsection{Lake surface temperature observations}

The lakes investigated in this study were selected based on the availability of near-continuous long-term observations of lake surface water temperature during all seasons as well as the criteria 
mentioned above. The study addresses eight lakes in Europe, situated in Ireland (1), the UK (5), Austria (1) and Switzerland (1) (Table 1). The lakes investigated vary in their geographical and morphological characteristics. They range in altitude between 20 and $440 \mathrm{~m}$ above sea level, in surface area between 0.1 and $67.0 \mathrm{~km}^{2}$ and in mean depth between 3.9 and $49 \mathrm{~m}$ (Table 1). The lake surface water temperature data sequences available from each of these lakes are some of the longest available from anywhere in the world. The majority of the data were collected between 1973 and 2014. Specific details of the temperature observations for each lake are provided below, and the lake surface water temperature data used in this study is available online.

Lake surface temperature data from Lough Feeagh (County Mayo, Ireland; 53.945 ${ }^{\circ} \mathrm{N},-$ $9.576^{\circ} \mathrm{E}$ ) were recorded at a site $60 \mathrm{~m}$ along the outflow, which was sampled daily at a depth of $<1 \mathrm{~m}$. Lake surface temperature recordings were continuous, via in situ paper or sensorbased recorders, and compiled daily. From 1960 to 2004, a paper chart recorder with a mercury thermometer was used. From 2004 to 2009, a StowAway TidbiT temperature data logger from Onset (TB132-05+37) was used. From 2009 to the present day, data were collected using a temperature sensor on an Orpheus Mini Water Level Recorder from OTT Hydrometry (http://www.ott.com/products/water-level-1/ott-orpheus-mini-water-level-logger-3/). For all data sources, the midnight temperatures were extracted each day. When sensors were changed in 2004 and 2009, overlapping data were used to confirm that there were no significant jumps in the data that would introduce bias to the long-term trend.

Lake surface temperatures were measured in four adjacent lake basins of different sizes within the English Lake District, UK: Blelham Tarn $\left(54.396^{\circ} \mathrm{N},-2.977^{\circ} \mathrm{E}\right)$, Esthwaite Water $\left(54.363^{\circ} \mathrm{N},-2.987^{\circ} \mathrm{E}\right)$, Windermere North Basin $\left(54.379^{\circ} \mathrm{N},-2.934^{\circ} \mathrm{E}\right)$ and Windermere South Basin $\left(54.316^{\circ} \mathrm{N},-2.951^{\circ} \mathrm{E}\right)$ (Maberly and Elliott 2012). Lake surface temperatures were recorded at weekly or two-weekly intervals in the morning, typically between 10:00 and 12:00, just below the surface at the deepest point in each basin. A range of sensors, all checked periodically with high-precision thermistors, were used to measure water temperature between 1947 and 2015 (George et al. 2004).

Loch Leven, situated in Scotland, UK $\left(56.197^{\circ} \mathrm{N},-3.378^{\circ} \mathrm{E}\right)$, was sampled bi-weekly and from the subsurface at an approximate depth of $0.01 \mathrm{~m}$. Lake surface temperatures were recorded in the morning, typically between 10:00 and 12:00 with a mercury-in-glass thermometer in a Ruttner closing bottle or with digital temperature probes that were all cross checked for accuracy against a certified mercury-in-glass thermometer with an accuracy of $0.1{ }^{\circ} \mathrm{C}$. Data were taken from one of two sites, one in open water at Reed Bower, a long-term monitoring site with a depth that corresponds to the mean depth of the lake (i.e., $3.9 \mathrm{~m}$ ), and the other at the outflow. These were sampled interchangeably, depending on weather conditions. As Loch Leven is relatively small and well mixed, surface temperature within the lake changes consistently across its area. Specifically, a comparison of fortnightly observations from both sampling locations in Leven from 1988 to 2015 shows a strong linear relationship (Fig. S1; $r^{2}=0.99$ ). This demonstrated that there is minimal intra-lake heterogeneity of surface water temperature responses to climate change at the site, in contrast to the situation that has been reported in some large lakes across the Northern Hemisphere (Woolway and Merchant 2018). So, we do not expect any biases to be introduced to the calculated long-term trends as a result of changes in the sampling locations.

Lake surface temperature data from Wörthersee, Austria $\left(46.628^{\circ} \mathrm{N}, 14.127^{\circ} \mathrm{E}\right)$ were extracted from the yearbooks of the hydrographic service Austria. Lake temperature data were collected daily at a depth of $\sim 0.2 \mathrm{~m}$ and obtained from the lake level gauging station. Sampling was performed between 08:00 and 10:00 throughout the observational period. 


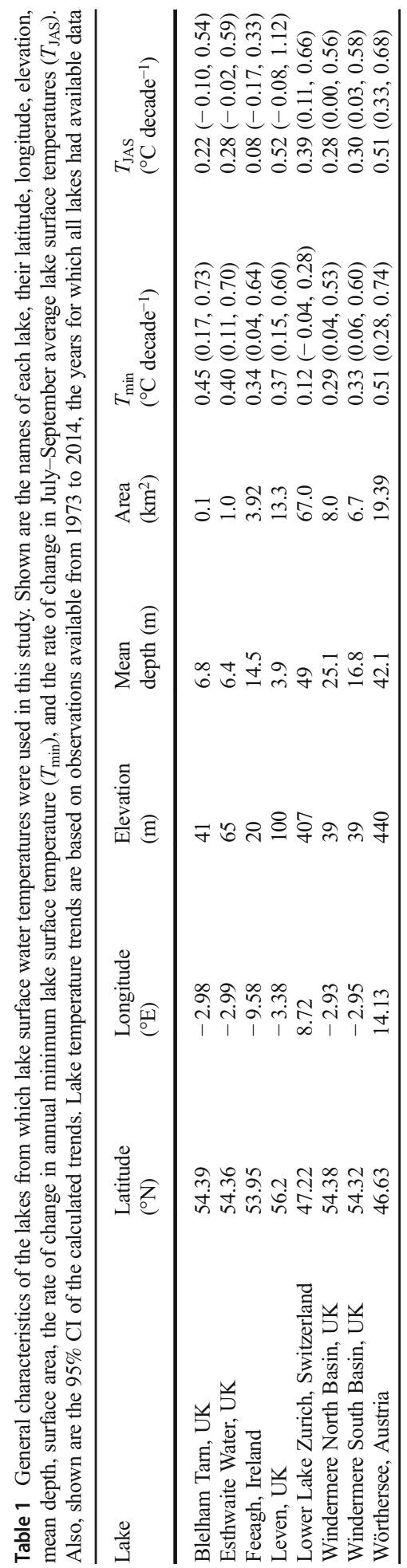


Methodological changes due to sensors, timing or station modifications have been carefully checked and compensated by the hydrologists collecting the data.

Lake surface temperatures in Lower Lake Zurich $\left(47.223^{\circ} \mathrm{N}, 8.723^{\circ} \mathrm{E}\right)$ were provided by the City of Zurich Water Supply and by the Amt für Abfall, Wasser, Energie und Luft (AWEL) of the Canton of Zurich. Temperatures until 1971 were measured by the laboratories of the Canton and the City of Zurich and later included in the database of AWEL. Temperatures were measured at approximately monthly intervals at the deepest point of the lake and at depths of approximately $0.05-0.15 \mathrm{~m}$ until 2000 and approximately $0.1-0.3 \mathrm{~m}$ thereafter. Temperature measurements were taken at approximately 10:00. Between 1945 and January 2001, a range of sensors were used to measure water temperature at discrete depths, mainly involving thermistors. From February 2001 to July 2008, an FLP-10 multisonde (DMP AG, Switzerland) was used and from August 2008 onwards using a Hydrolab DS5 multisonde (OTT Hydromet GmbH, Germany). All instruments were regularly calibrated, and measurements are expected to be correct within $0.1{ }^{\circ} \mathrm{C}$. A detailed description of the data collected at Lower Lake Zurich is also given by Sharma et al. (2015) and by Peeters et al. (2002). We analyse lake temperature data from 1945 to 2017 in this study. The monthly sampling interval in Lower Lake Zurich likely introduces some bias and uncertainty to the analysis, as it is unlikely that the lowest temperature was actually recorded for any given year. Although we decided to include data from Lower Lake Zurich in this study, the low sampling frequency must be taken into consideration when interpreting the results. In winter 1962/1963, Lower Lake Zurich was ice-covered for more than a month. Temperature sampling was interrupted during this time and, thus, is not included in this analysis. This was the only time during the study period where ice was present on the studied lakes.

The consistency in the time of day at which the surface temperature measurements were made in each lake is essential to ensure that no biases are introduced to the time series as a result of the large diel variability in surface water temperature (Woolway et al. 2015a, 2016). This consistency over the $>40$ years in each studied lake allows the changes over time to be interpreted with confidence. A limitation of the lake surface temperature measurements is that only one observation was available per day in the studied lakes. Therefore, it is likely that the lowest temperature (i.e., minimum) on a given day could have been missed. In addition, the time of day during which the surface temperature measurements were taken differ among the studied lakes, an inconsistency to bear in mind while interpreting the across-lake comparisons and when generalising these results to other lakes.

\subsection{Surface air temperature observations}

In this study, we inform our lake surface temperature analysis using air temperature observations from HadISD (Dunn et al. 2012), which is a quality-controlled synoptic meteorological dataset used for climate applications at subdaily resolution (https://www.metoffice.gov. $\mathrm{uk} /$ hadobs/hadisd/). Air temperature observations for each lake were selected from the nearest meteorological station within the HadISD dataset (all within $80 \mathrm{~km}$ of the lake). Data are available from 1973 to the present day. As a measure of mean climatic conditions near each lake throughout the study period, we compared the calculated annual minimum lake surface temperatures with air temperatures averaged over 1 month prior to the day of year in which the minimum lake surface temperature occurred. This averaging period is used to account for the fact that lake surface temperatures are responsive to air temperature anomalies (in addition to other meteorological forcing) on longer than daily time scales, since the lake integrates the daily heat flux over time (Piccolroaz et al. 2013; Woolway et al. $2015 b$ ). One caveat to this, however, is that the duration during which lake surface temperature 
anomalies are influenced by air temperature anomalies can differ between lakes, with deeper lakes being responsive to air temperature variations on longer timescales (Woolway and Merchant 2017). Nonetheless, in this study, we use 1 month as an approximate period during which lake surface temperatures are influenced by air temperature variations.

\subsection{Statistical methods}

We analysed long-term trends using ordinary least-squares linear regression models. Trends were estimated as the slope of a linear trend model using data from 1973 to 2014, the years in which all lakes had observations. A LOWESS smoother was used to illustrate long-term change in the annual minimum lake surface temperature. All calculations in this study were performed using R version 3.5.1 (R Development Core Team 2018).

For lakes with daily observations of lake surface temperature, we estimated how the frequency of temperature observations, which varied among the lakes, influenced the trend and inter-annual variability in the computed annual minimum lake surface water temperature. Specifically, we reduced the sampling frequency from daily to 21 days at 1-day increments and re-calculated the annual minimum lake surface temperature. The down-sampled data were then compared to the original time series.

Annual minimum lake surface temperatures were compared with the more frequently studied warm season lake surface temperatures, which we define in this study as the JulySeptember averages, in-line with previous lake surface temperature studies (Schneider and Hook 2010; O’Reilly et al. 2015; Woolway and Merchant 2017).

\section{Results}

Lake surface temperature records investigated in this study showed a substantial increase in annual minimum temperatures during the historic period (Fig. 1). All of the studied lakes experienced a relatively steady increase in annual minimum lake surface temperature, notwithstanding substantial inter-annual variability. Also noteworthy are the lakes for which the number of years in which the annual minimum lake surface temperature cooled to $4{ }^{\circ} \mathrm{C}$, near the temperature of maximum density of fresh water, has decreased (Fig. 1). For example, Windermere North Basin no longer cools to $4{ }^{\circ} \mathrm{C}$ each year, and the minimum temperature of other lakes, such as Wörthersee, is approaching rapidly this temperature threshold.

A positive least-squares trend was calculated for the annual minimum surface temperature in each lake from 1973 to 2014, the years in which all lakes had available data (Table 1). The average rate of change across the eight lakes during this period was $+0.35{ }^{\circ} \mathrm{C}$ decade $^{-1}(95 \%$ $\mathrm{CI}$ of the average: $0.27,0.43$ ), with the rates of change varying among lakes between + $0.12{ }^{\circ} \mathrm{C} \mathrm{decade}^{-1}$ (Lower Lake Zurich) and $+0.51{ }^{\circ} \mathrm{C}$ decade $^{-1}$ (Wörthersee). Strong correlations between the annual minimum lake surface temperature and the site-specific surface air temperatures, averaged over 1 month prior to the day of year in which the minimum lake surface temperature occurred, were calculated (Fig. 2). When local air temperatures were anomalously high, the annual minimum lake surface temperature was also higher. The correlation between air temperature and annual minimum lake surface temperature in some lakes, such as Windermere North Basin, was strong $\left(r^{2}=0.60\right)$, illustrating that a large proportion of the inter-annual variability in annual minimum lake surface temperature is explained by air temperature changes at that time of year. 

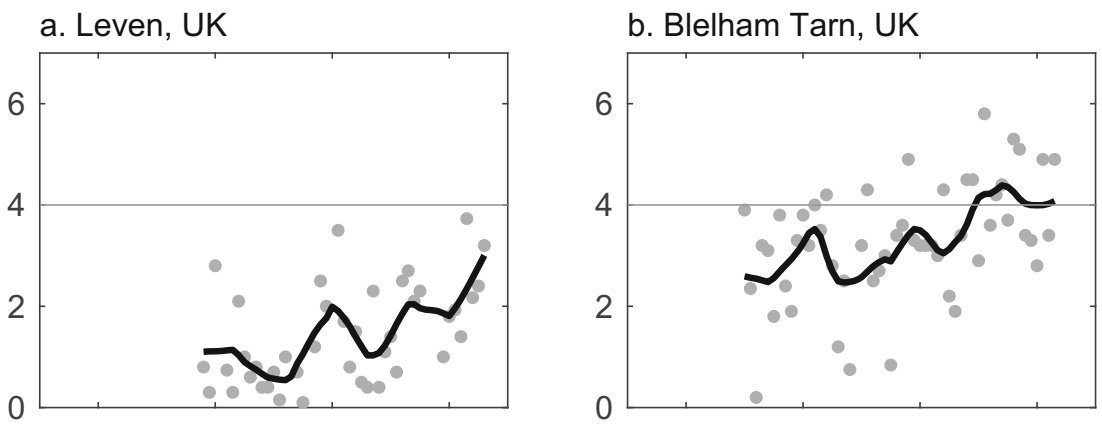

c. Windermere North, UK

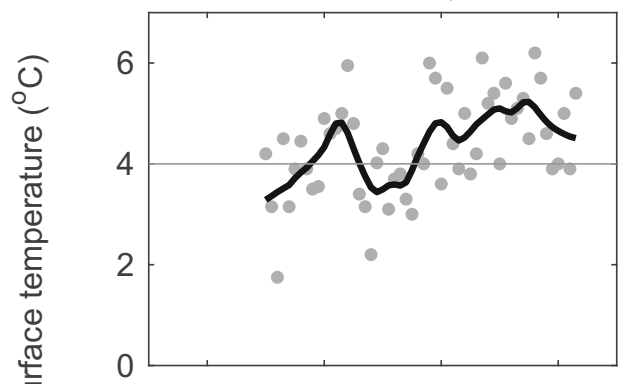

d. Esthwaite Water, UK

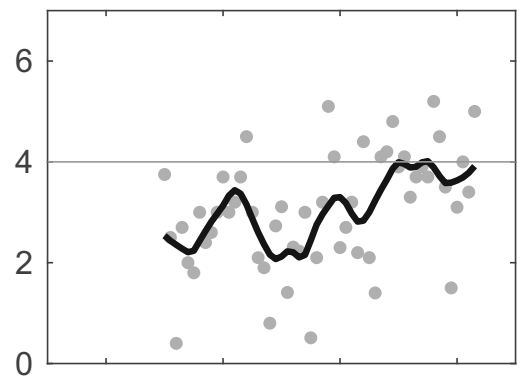

e. Windermere South, UK

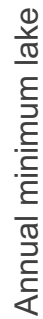

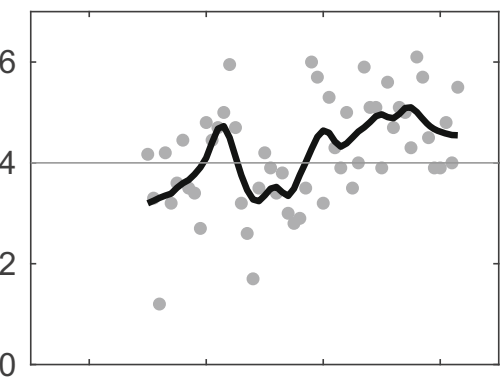

f. Feeagh, Ireland

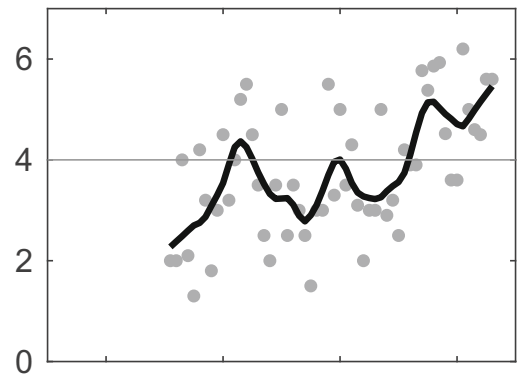

g. Zurich, Switzerland

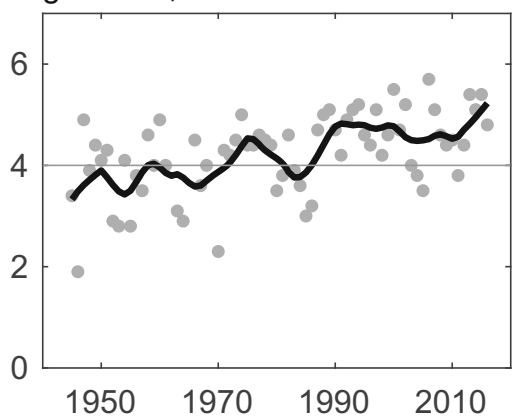

h. Wörthersee, Austria

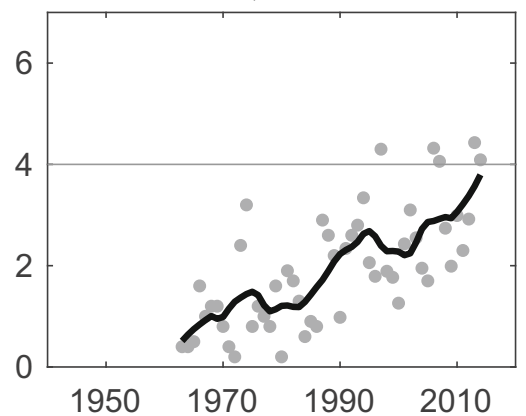

Fig. 1 Annual minimum lake surface water temperature for each lake investigated in this study. The annual minimum lake surface temperatures are shown by the grey points and the LOWESS smoother (11-year span) is shown by the solid black line. The horizontal grey line illustrates an annual minimum lake surface temperature of $4{ }^{\circ}$ C. a Leven, UK. b Blelham Tarn, UK. c Windermere North, UK. d Esthwaite Water, UK. e Windermere South, UK. f Feeagh, Ireland. g Zurich, Switzerland. h Wörthersee, Austria 

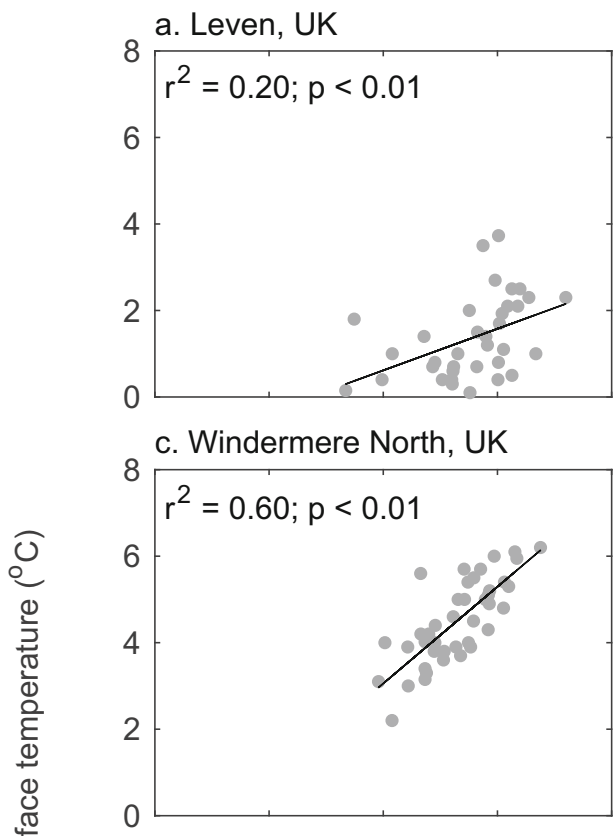

e. Windermere South, UK
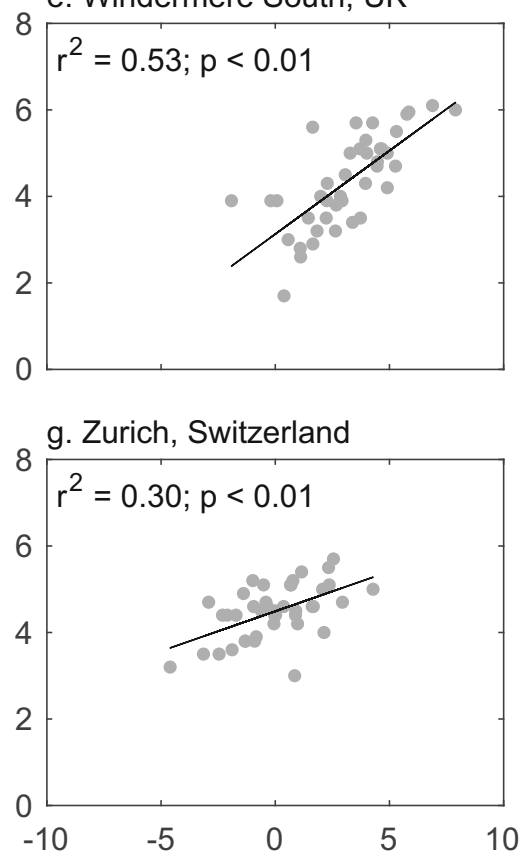

b. Blelham Tarn, UK

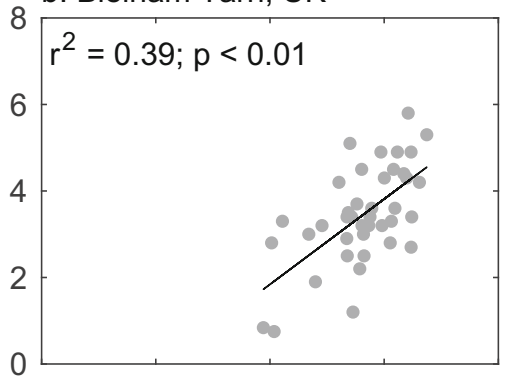

d. Esthwaite Water, UK

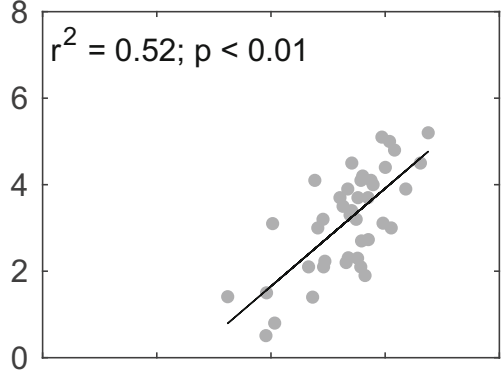

f. Feeagh, Ireland

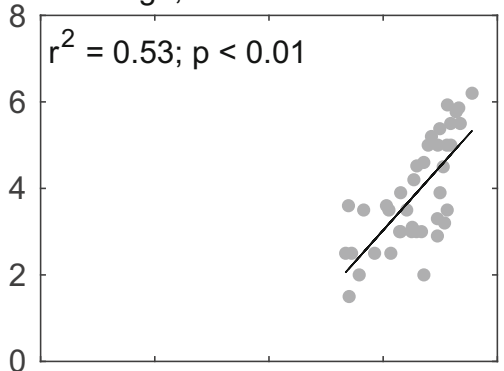

h. Wörthersee, Austria

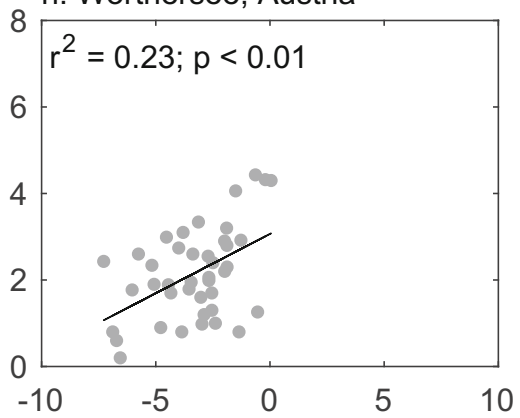

Average surface air temperature $\left({ }^{\circ} \mathrm{C}\right)$

Fig. 2 Relationship between the annual minimum of lake surface water temperature and air temperatures averaged over 1 month prior to the day of year in which the minimum lake surface temperature occurred. Linear regressions are also illustrated (black line) and the calculated correlation coefficient $\left(r^{2}\right)$ is shown. a Leven, UK. b Blelham Tarn, UK. c Windermere North, UK. d Esthwaite Water, UK. e Windermere South, UK. f Feeagh, Ireland. g Zurich, Switzerland. h Wörthersee, Austria 
For lakes with available daily surface water temperature observations (Feeagh and Wörthersee), we investigated the influence of sampling frequency on the inter-annual variability and the rate of change in annual minimum lake surface temperature (Fig. 3). We found that down-sampling the daily lake surface temperature observations to a 21-day sampling frequency does not influence the calculated rate of change in annual minimum surface temperature in these lakes. Specifically, the calculated rate of change of the down-sampled data lies within the $95 \%$ confidence interval of the rate of change calculated with daily observations. However, the representativeness of the interannual variability in annual minimum lake surface temperature decreases with a decrease in sampling frequency (Fig. 3). In particular, the computed correlation coefficient between the annual minimum lake surface temperature calculated from the daily data and that calculated from the down-sampled time series decreases with a decrease in sampling frequency.

The rate of change in annual minimum lake surface temperature is comparable to, but not correlated with, the rate of change in July-September average lake surface temperature (Fig. 4). During July-September, all lakes showed a positive least-squares trend in their surface temperature between 1973 and 2014 (Table 1). The average rate of change across the eight lakes during this

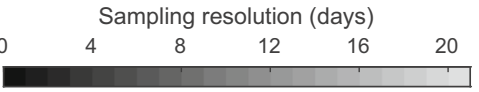

Feeagh, Ireland

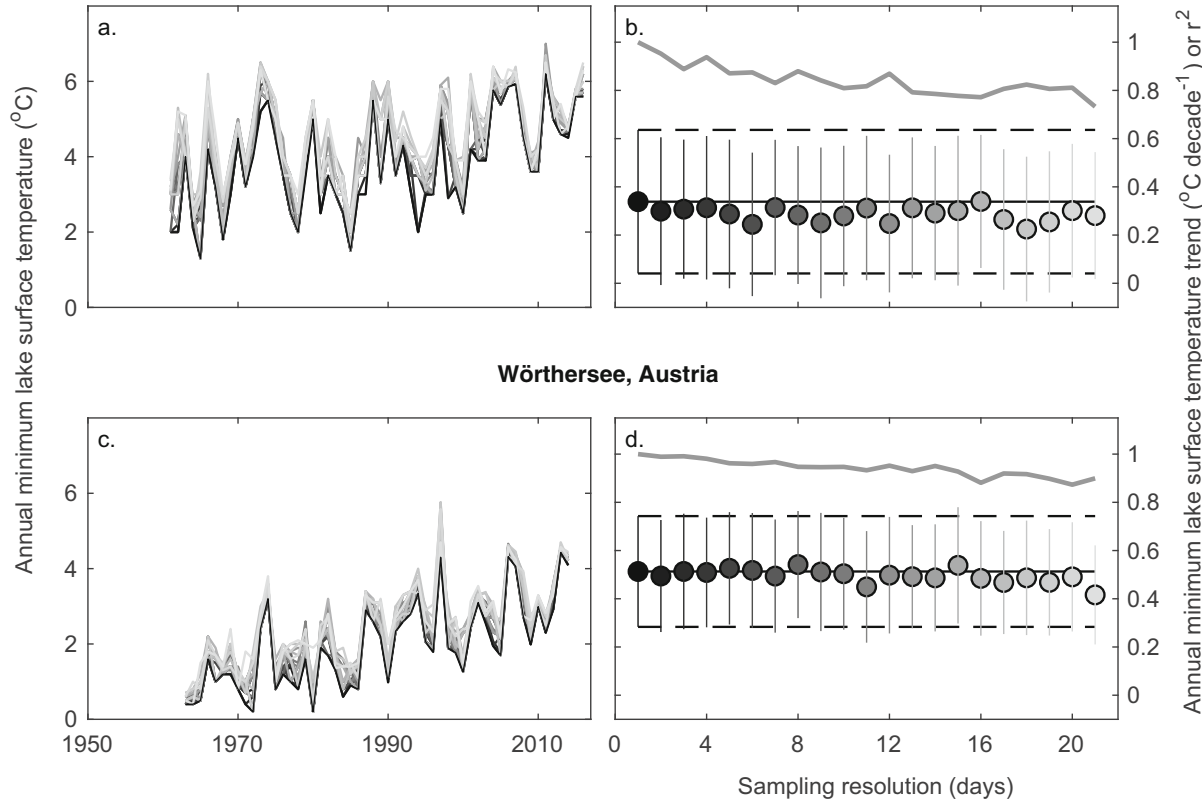

Fig. 3 Comparison of the calculated annual minimum lake surface water temperature from the observed data (as shown in Fig. 1) with those calculated from a time series whereby the sampling frequency was reduced from daily to 21 days at 1-day increments. Shown are a, $\mathbf{c}$ the inter-annual variability in the annual minimum observed and downsampled lake surface water temperature time series and $\mathbf{b}, \mathbf{d}$ the calculated rate of change in minimum lake surface temperature from 1973 to 2014. In b and d, the solid black horizontal line represents the calculated rate of change from the observed annual minimum temperature, and the dashed lines represent the $95 \%$ confidence interval (Table 1). Note that a sampling resolution of 1-day is equal to the raw daily data. Lake temperatures are shown only for lakes with daily lake surface temperature observations: a, b Feeagh, Ireland, and c, d Wörthersee, Austria. The grey lines in $\mathbf{b}$ and $\mathbf{d}$ show the computed correlation coefficients $\left(r^{2}\right)$ between the observed annual minimum lake surface water temperature and that calculated from the down-sampled time series (as shown in a and c) 
period was $+0.32{ }^{\circ} \mathrm{C}$ decade $^{-1}(95 \% \mathrm{CI}$ of the average $0.22,0.42)$, with the rates of change varying among lakes between $+0.08^{\circ} \mathrm{C}$ decade $^{-1}$ (Feeagh) and $+0.52^{\circ} \mathrm{C} \mathrm{decade}^{-1}$ (Leven). In some lakes, such as those situated in the UK (Blelham Tarn and Esthwaite Water) and Ireland (Feeagh), the increase in annual minimum lake surface temperature is considerably higher than the rate of change in July-September averaged surface temperatures. Annual minimum surface temperatures in Blelham Tarn are increasing at a rate approximately twice that of the July-September surface temperature change, and in Feeagh, annual minimum lake surface temperatures are increasing four times faster than July-September surface temperature averages (Fig. 4).

\section{Discussion}

We investigated the influence of climate change on the annual minimum surface water temperature of some of Europe's best monitored lakes. Lake surface water temperature responses to climate change had been investigated previously, but our study is the first to investigate and compare annual minimum lake surface temperatures using long-term observational data from numerous lakes. Based on these long-term observations, we found a largescale increase in annual minimum surface temperature, with an average warming rate of + $0.35{ }^{\circ} \mathrm{C} \mathrm{decade}{ }^{-1}$ (range +0.12 to $+0.51{ }^{\circ} \mathrm{C}$ decade $^{-1}$ ) across eight study lakes in Europe.

The increase in annual minimum lake surface temperatures observed in this study correlated with the inter-annual variability in winter air temperature. A perfect fit between these temperature time series was not expected due to climate-induced changes in other variables such as wind speed (Woolway et al. 2017b) and solar radiation (Schmid and Köster 2016) that can influence greatly the lake surface energy budget and, thus, lake surface water temperature. However, the strong correlations imply that changes in winter air temperature have an important influence on the minimum lake surface temperature attained within a given year.

The impacts of increasing annual minimum surface temperatures on lakes differ but are likely to be as important as the impacts of increases in summer-average lake surface temperature

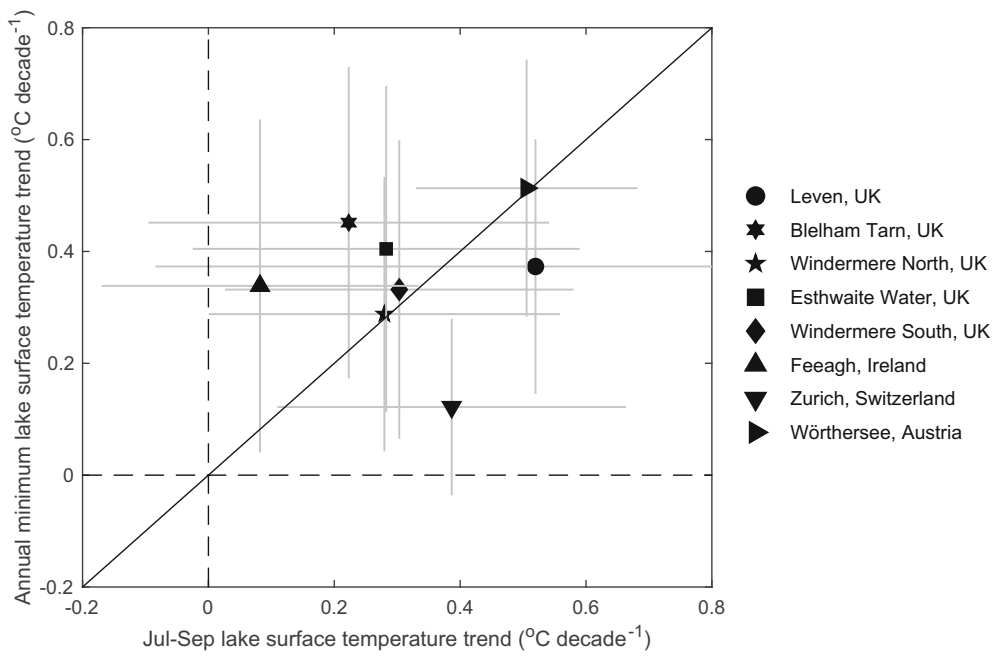

Fig. 4 Comparison of the rate of change in July-September average lake surface temperature and the rate of change in annual minimum lake surface temperature. The grey lines represent the $95 \%$ confidence interval of the calculated trends. The black diagonal line gives the 1:1 relationship 
warming $\left(+0.32{ }^{\circ} \mathrm{C}\right.$ decade $\left.{ }^{-1}\right)$, which has been more widely studied globally (O'Reilly et al. 2015). An increase in the annual minimum lake surface temperature can imply that a critical temperature threshold is crossed. One of the most important surface temperature thresholds in lakes with regard to physical lake processes is $4{ }^{\circ} \mathrm{C}$, the temperature of maximum density of freshwater. This is especially critical for deep monomictic lakes as it has a direct influence on the duration of the period of homothermy during which a lake can mix fully in winter as well as the depth of mixing. In particular, if the surface temperature of deep lakes does not fall to $4{ }^{\circ} \mathrm{C}$, positive stratification can persist from one summer to the next without interruption, inhibiting complete turnover and resulting in deepwater carryover (Peeters et al. 2002). This, in turn, results in a warming of the hypolimnion (Livingstone 2003; Dokulil et al. 2006) and reduced replenishment of deepwater dissolved oxygen (Livingstone 1997; Straile et al. 2003; Rempfer et al. 2010). There is some evidence that this may, indeed, already be taking place, with deeply penetrative mixing being suppressed in some traditionally monomictic lakes during increasingly mild winters (Livingstone 1993; Peeters et al. 2002; Woolway and Merchant 2019), resulting in a decrease in deepwater oxygen concentrations (North et al. 2014). Oxygen depletion and high hypolimnetic temperatures can also affect other biogeochemical processes in lakes resulting in, for example, enhanced nutrient release at the sediment-water interface (Marsden 1989; Søndergaard et al. 2003). The lack of complete mixing can also cause reduced phosphorus availability in the surface water of lakes at the beginning of the growing season or create different initial conditions for some algal groups in spring (Yankova et al. 2017).

Rising minimum lake temperatures will also change habitats for cold water species (McGinnity et al. 2009; de Eyto et al. 2016). For some glacial relict species which rely on cold winter temperatures as climate refugia, such as the Opossum shrimp Mysis salemaai and the Arctic charr Salvelinus alpinus, cold water temperatures are important for survival (Elliott and Elliott 2010; Penk et al. 2015) and such species decline rapidly when lake waters no longer reach "cold water" temperatures (Jeppesen et al. 2009). For example, rising winter lake temperatures have been linked to the disappearance of Arctic charr from Lake Vättern (Jonsson and Setzer 2015).

Rising minimum temperatures, as shown in this study, imply that periods of warmer surface water temperatures are extended during winter. Such extended periods will affect the phenology of phytoplankton, zooplankton and even fish (Weyhenmeyer 2001; Thackeray et al. 2016; Hansen et al. 2017) and could also result in a mismatch of species interactions (Adrian et al. 2006; Thackeray et al. 2013). Ultimately, the warming will affect the rate of primary production, the rate of decomposition and the appearance of cyanobacteria (Robarts and Zohary 1987).

Our finding of an increase in annual minimum lake surface water temperature is applicable to other lakes globally, exclusively to lakes that do not experience ice cover and those situated in regions where winter air temperatures are increasing. The number of ice-free lakes worldwide is expected to increase with climatic warming (Sharma et al. 2019); thus, we further anticipate an increase in the number of lakes that experience a warming of annual minimum lake surface temperatures in the future. Our sensitivity analysis demonstrated that sampling frequency does not influence considerably the calculated rate of change in annual minimum lake surface temperature. Thus, there are good prospects for investigating annual minimum lake temperature changes in other lakes, even when daily observational data are not available. Increasing the study region to a global scale would help generalise the trends shown for lakes in this study, which did not differ considerably in terms of their size, depth and location, relative to lakes worldwide (Messager et al. 2016). Understanding, predicting and quantifying the thermal response of lakes to abrupt and gradual climate change are critical for future decision-making involving water resource management policies and to understand how lake ecosystems will respond in the future. 


\section{Conclusions}

Lake surface water temperature observations were analysed to investigate how annual minimum lake surface temperatures have responded to climate change and, in particular, an increase in winter air temperatures. Our results show, for many lakes, a rapid warming of annual minimum lake surface temperatures, with an average surface warming rate of $+0.35{ }^{\circ} \mathrm{C}$ decade $^{-1}$ between 1973 and 2014. Such an increase can have a substantial influence on a lake ecosystem. For example, it can influence the length of the growing season with consequent increases in bacterial and phytoplankton productivity. It can also decrease or even cause the loss of cold stenothermic species and disrupt food web structures leading to a possible mismatch of species interactions. Some aquatic ecosystems may be able to adapt to the observed changes in temperature extremes; however, possible regime shifts need to be taken into consideration during climate change discussions.

Acknowledgements We would like to thank the numerous individuals who contributed to many decades of lake temperature measurements in each of the lakes included in this investigation. The Freshwater Biological Association collected lake temperature data in the English Lake District prior to 1989 and the NERC Centre for Ecology \& Hydrology subsequently. Data for Loch Leven were collected by staff from the NERC Centre for Ecology \& Hydrology, Edinburgh. The staff of the Marine Institute in Ireland (and formerly the SRT and SRAI) collected the data from Lough Feeagh. Temperatures for Lake Zurich were provided by the City of Zurich Water Supply and by the Amt für Abfall, Wasser, Energie und Luft of the Canton of Zurich. We thank Mr. Christian Kopeinig from The Hydrographical Service Carinthia for providing long-term data from Wörthersee. This work benefited from participation in the Global Lake Ecological Observatory Network (GLEON).

Funding information This analysis was funded by EUSTACE (EU Surface Temperature for All Corners of Earth) which has received funding from the European Union's Horizon 2020 Programme for Research and Innovation, under Grant Agreement no 640171. RIW received funding from a European Union's Marie Skłodowska-Curie Individual Fellowship (\#791812; INTEL project).

Open Access This article is distributed under the terms of the Creative Commons Attribution 4.0 International License (http://creativecommons.org/licenses/by/4.0/), which permits unrestricted use, distribution, and reproduction in any medium, provided you give appropriate credit to the original author(s) and the source, provide a link to the Creative Commons license, and indicate if changes were made.

\section{References}

Adrian R, Wilhelm S, Gerten D (2006) Life history traits of lake plankton species may govern their phenological response to climate warming. Glob Chang Biol 12:652-661

Austin JA, Colman SM (2007) Lake Superior summer water temperatures are increasing more rapidly than regional temperatures: a positive ice-albedo feedback. Geophys Res Lett 34. https://doi.org/10.1029/2006GL029021

Dokulil MT, Jagsch A, George G et al (2006) Twenty years of spatially coherent deep-water warming in lakes across Europe related to the North Atlantic Oscillation. Limnol Oceanogr 51:2787-2793

Dunn RJH, Willett KM, Thorne PW et al (2012) HadISD: a quality-controlled global synoptic report database for selected variables at long-term stations from 1973-2011. Clim Past 8:1649-1679

Elliott JM, Elliott JA (2010) Temperature requirements of Atlantic salmon Salmo salar, brown trout Salmo trutta and Arctic charr Salvelinus alpinus: predicting the effects of climate change. J Fish Biol 77:1793-1817

Elo A-R, Huttula T, Peltonen A, Virta J (1998) The effects of climate change on the temperature conditions of lakes. Boreal Environ Res 3:137-150

de Eyto E, Dalton C, Dillane M et al (2016) The response of North Atlantic diadromous fish to multiple stressors, including land use change: a multidecadal study. Can J Fish Aquat Sci 73:1759-1769 
Fang X, Stefan HG (1999) Projections of climate change effects on water temperature characteristics of small lakes in the contiguous U.S. Clim Chang 42:377-412

George DG, Maberly SC, Hewitt DP (2004) The influence of the North Atlantic Oscillation on the physics, chemistry and biology of four lakes in the English Lake District. Freshw Biol 49:760-774

Hampton SE, Galloway AWE, Powers SN et al (2017) Ecology under lake ice. Ecol Lett 20:98-111

Hansen GJA, Read JS, Hansen JF, Winslow LA (2017) Projected shifts in fish species dominance in Wisconsin lakes under climate change. Glob Chang Biol 23:1463-1476

Jeppesen E, Kronvang B, Meerhoff M et al (2009) Climate change effects on runoff, catchment phosphorus loading and lake ecological state, and potential adaptations. J Environ Qual 38:1930-1941

Jonsson T, Setzer M (2015) A freshwater predator hit twice by the effects of warming across trophic levels. Nat Commun 6:5992

Lenters JD (2004) Trends in the Lake Superior water budget since 1948: a weakening seasonal cycle. J Great Lakes Res 30:20-40

Livingstone DM (1993) Temporal structure in the deep-water temperature of four Swiss lakes: a short-term climatic change indicator? Verh Internat Verein Limnol 25:75-81

Livingstone DM (1997) An example of the simultaneous occurrence of climate-driven 'saw-tooth' deep-water warming/cooling episodes in several Swiss lakes. Verh Internat Verein Limnol 26:822-828

Livingstone DM (2003) Impact of secular climate change on the thermal structure of a large temperate central European lake. Clim Chang 57:205-225

Maberly SC, Elliott JA (2012) Insights from long-term studies in the Windermere catchment: external stressors, internal interactions and the structure and function of lake ecosystems. Freshw Biol 57:233-243

Magee MR, Wu CH, Robertson DM et al (2016) Trends and abrupt changes in 104 years of ice cover and water temperature in a dimictic lake in response to air temperature, wind speed, and water clarity drivers. Hydrol Earth Syst Sci 20:1681-1702

Marsden HW (1989) Lake restoration by reducing external phosphorus loading: the influence of sediment phosphorus release. Freshw Biol 21:139-162

McGinnity P, Jennings E, de Eyto E et al (2009) Impact of naturally spawning captive-bred Atlantic salmon on wild populations: depressed recruitment and increased risk of climate-mediated extinction. Proc R Soc Lond Biol 283:3601-3610

Messager ML et al (2016) Estimating the volume and age of water stored in global lakes using a geo-statistical approach. Nat Commun 7:13603

North RP, North RL, Livingstone DM et al (2014) Long-term changes in hypoxia and soluble reactive phosphorus in the hypolimnion of a large temperate lake: consequences of a climate regime shift. Glob Chang Biol 20:811-823

O'Reilly C, Sharma S, Gray DK et al (2015) Rapid and highly variable warming of lake surface waters around the globe. Geophys Res Lett 42:10773-10781

Peeters F, Livingstone DM, Goudsmit G-H et al (2002) Modeling 50 years of historical temperature profiles in a large central European lake. Limnol Oceanogr 47:186-197

Penk M, Donohue I, Récoules V, Irvine K (2015) Elevated temperatures interact with habitat quality to undermine survival of ectotherms in climatic refugia. Divers Distrib 21:200-210

Piccolroaz S, Toffolon M, Majone B (2013) A simple lumped model to convert air temperature into surface water temperature in lakes. Hydrol Earth Syst Sci 17:3323-3338

R Development Core Team (2018) R: a language and environment for statistical computing. R Foundation for Statistical Computing, Vienna [Available at http://www.R-project.org/]

Rempfer J, Livingstone DM, Blodau C et al (2010) The effect of the exceptionally mild European winter of 2006-2007 on temperature and oxygen profiles in lakes in Switzerland: a foretaste of the future? Limnol Oceanogr 55:2170-2180

Robarts RD, Zohary T (1987) Temperature effects on photosynthetic capacity, respiration, and growth rates of bloom-forming cyanobacteria. New Zeal J Mar Fresh 21:391-399

Schmid M, Köster O (2016) Excess warming of a Central European lake by solar brightening. Water Resour Res 52:8103-8116

Schneider P, Hook SJ (2010) Space observations of inland water bodies show rapid surface warming since 1985. Geophys Res Lett 37:L22405. https://doi.org/10.1029/2010GL045059

Sharma S, Gray DK, Read JS et al (2015) A global database of lake surface temperatures collected by in situ and satellite methods from 1985-2009. Sci Data 2:150008

Sharma S, Blagrave K, Magnuson JJ et al (2019) Widespread loss of lake ice around the Northern Hemisphere in a warming world. Nat Clim Chang 9:227-231

Søndergaard M, Jensen JP, Jeppesen E (2003) Role of sediment and internal loading of phosphorus in shallow lakes. Hydrobiologia 506:135-145 
Straile D, Stenseth NC (2007) The North Atlantic oscillation and ecology: links between historical time-series, and lessons regarding future climate warming. Clim Res 34:259-262

Straile D, Joehnk K, Rossknecht H (2003) Complex effects of winter warming on the physic-chemical characteristics of a deep lake. Limnol Oceanogr 48:1432-1438

Straile D, Kerimoglu O, Peeters F et al (2010) Effects of a half a millennium winter on a deep lake - a shape of things to come? Glob Chang Biol 16:2844-2856

Thackeray SJ, Henrys PA, Feuchtmayr H et al (2013) Food web de-synchronisation in England's largest lake: an assessment based on multiple phenological metrics. Glob Chang Biol 19:3568-3580

Thackeray SJ, Henrys PA, Hemming D et al (2016) Phenological sensitivity to climate across taxa and trophic levels. Nature 535:241-245

Weyhenmeyer GA (2001) Warmer winters: are planktonic algal populations in Sweden's largest lakes affected? Ambio 30:565-571

Winslow LA, Read JS, Hansen GJA et al (2017) Seasonality of change: summer warming rates do not fully represent effects of climate change on lake temperatures. Limnol Oceanogr 62:2168-2178

Woolway RI, Merchant CJ (2017) Amplified surface temperature response of cold, deep lakes to inter-annual air temperature variability. Sci Rep 7:4130

Woolway RI, Merchant CJ (2018) Intra-lake heterogeneity of thermal responses to climate change: a study of large Northern Hemisphere lakes. J Geophys Res Atmos 123:3087-3098

Woolway RI, Merchant CJ (2019) Worldwide alteration of lake mixing regimes in response to climate change. Nat Geosci 12:271-276

Woolway RI, Jones ID, Feuchtmayr H, Maberly SC (2015a) A comparison of the diel variability in epilimnetic temperature for five lakes in the English Lake District. Inland Waters 5:139-154

Woolway RI, Jones ID, Hamilton DP, Maberly SC, Muraoka K, Read JS, Smyth RL, Winslow LA (2015b) Automated calculation of surface energy fluxes with high-frequency lake buoy data. Environ Model Softw 70:191-198

Woolway RI, Jones ID, Maberly SC et al (2016) Diel surface temperature range scales with lake size. PLoS One 11(3):e0152466

Woolway RI, Dokulil MT, Marszelewski W et al (2017a) Warming of Central European lakes and their response to the 1980s climate regime shift. Clim Chang 142:505-520

Woolway RI, Meinson P, Nõges P, Jones ID, Laas A (2017b) Atmospheric stilling leads to prolonged thermal stratification in a large shallow polymictic lake. Clim Chang 141:759-773

Yankova Y, Neuenschwander S, Köster O, Posch T (2017) Abrupt stop of deep water turnover with lake warming: drastic consequences for algal primary producers. Sci Rep 7:13770

Publisher's note Springer Nature remains neutral with regard to jurisdictional claims in published maps and institutional affiliations.

\section{Affiliations}

\section{R. lestyn Woolway ${ }^{1,2} \cdot$ Gesa A. Weyhenmeyer ${ }^{3} \cdot$ Martin Schmid $^{4} \cdot$ Martin T. Dokulil $^{5}$. Elvira de Eyto ${ }^{6} \cdot$ Stephen C. Maberly $^{7} \cdot$ Linda May $^{8} \cdot$ Christopher J. Merchant $^{1,9}$}

1 Department of Meteorology, University of Reading, Reading, UK

2 Present address: Dundalk Institute of Technology, Dundalk, Co. Louth, Ireland

3 Department of Ecology and Genetics/Limnology, Uppsala Univesitet, Uppsala, Sweden

4 Surface Waters-Research and Management, Eawag: Swiss Federal Institute of Aquatic Science and Technology, Kastanienbaum, Switzerland

5 Research Department for Limnology, University of Innsbruck, Mondsee, Austria

6 Marine Institute, Furnace, Newport, Ireland

7 Centre for Ecology \& Hydrology, Lancaster, UK

8 Centre for Ecology \& Hydrology, Edinburgh, UK

9 National Centre for Earth Observation, University of Reading, Reading, UK 